\title{
Correction to: Out of the Black Box: Treatment of Resistant Depression in Adolescents and the Antidepressant Controversy by Wagner KD, Asarnow JR, Vitiello B, Clarke G, Keller M, Emslie GJ, Ryan N, Porta G, lyengar S, Ritz L, Zelanzny J, Onorato M, and Brent D. J Child Adolesc Psychopharmacol 22:5-10, 2012. DOI: $10.1089 /$ cap.2011.0045
}

N THE February 2012 issue of the Journal of Child and Adolescent Psychopharmacology (vol. 22, no. 1; 5-10) the article entitled "Out of the Black Box: Treatment of Resistant Depression in Adolescents and the Antidepressant Controversy" by Wagner et al. requires correction.

In the Conclusion section, the sentence read:

Nearly $60 \%$ had self-rated suicidal ideation at intake that was above the established clinical cut-offs.

The sentence now reads:

Nearly $\mathbf{4 0 \%}$ had self-rated suicidal ideation at intake that was above the established clinical cut-offs.

The online version has been corrected to reflect this. The authors apologize for this error. 